\title{
Automated detection of individual juniper tree location and forest cover changes using Google Earth Engine
}

\author{
Sudeera Wickramarathna', Jamon Van Den Hoek², Bogdan M. Strimbu1 ${ }^{\varpi}$
}

Wickramarathna S., Van Den Hoek J., Strimbu B.M., 2021. Automated detection of individual juniper tree location and forest cover changes using Google Earth Engine. Ann. For. Res. 64(1): 61-72.

Abstract Tree detection is the first step in the appraisal of a forest, especially when the focus is monitoring the growth of tree canopy. The acquisition of annual very high-resolution aerial images by the National Agriculture Imagery Program (NAIP) and their accessibility through Google Earth Engine (GEE) supports the delineation of tree canopies and change over time in a cost and time-effective manner. The objectives of this study are to develop an automated method to detect the crowns of individual western Juniper (Juniperus occidentalis) trees and to assess the change of forest cover from multispectral 1-meter resolution NAIP images collected from 2009 to 2016 in Oregon, USA. The Normalized Difference Vegetation Index (NDVI), Normalized Difference Water Index (NDWI), and Ratio Vegetation Index (RVI) were calculated from the NAIP images, in addition to the red-green-blue-near infrared bands. To identify the most suitable approach for individual tree crown identification, we created two training datasets: one considering yearly images separately and one merging all images, irrespective of the year. We segmented individual tree crowns using a random forest algorithm implemented in GEE and seven rasters, namely the reflectance of four spectral bands as recorded by the NAIP images (i.e., the red-green-blue-near infrared) and three calculated indices (i.e., NDVI, NDWI, and RVI). We compared the estimated location of the trees, computed as the centroid of the crown, with the visually identified treetops, which were considered as validation locations. We found that tree location errors were smaller when years were analyzed individually than by merging the years. Measurements of completeness $(74 \%)$, correctness (94\%), and mean accuracy detection (82\%) show promising performance of the random forest algorithm in crown delineation, considering that only four original input bands were used for crown segmentation. The change in the calculated crown area for western juniper follows a sinusoidal curve, with a decrease from 2011 to 2012 and an increase from 2012 to 2014. The proposed approach has the potential to estimate individual tree locations and forest cover area dynamics at broad spatial scales using regularly collected airborne imagery with easy-to-implement methods.

Keywords: random forests, NAIP imagery, individual tree crown segmentation, spectral indices

Addresses: ${ }^{1}$ Department of Forest Engineering, Resources, and Management, College of Forestry, Oregon State University, Corvallis, USA | ${ }^{2}$ Geography and Geospatial Science, College of Earth, Ocean, and Atmospheric Sciences, Oregon State University, Corvallis, USA.

Corresponding Author: Bogdan M. Strimbu (bogdan.strimbu@oregonstate.edu ).

Manuscript received February 2, 2020; revised June 17; accepted June 24, 2021. 


\section{Introduction}

To make informed management and conservation decisions about changes in forested landscapes, high spatial resolution data is desired (Gatziolis et al. 2015). Such images from airborne or spaceborne platforms allow identification of individual trees, which are the fundamental measurement unit on which the forest management is based on (Wang et al. 2004). Therefore, in the last two decades many applications of remote sensing in forestry have focused on tree-level forest inventory (Meyer \& Beucher 1990, Popescu et al. 2003), which provides beneficial outcomes compared to conventional forest inventory practices, particularly because they are less expensive for large areas. Among remote sensing methods focused on forest monitoring and management, delineation of individual tree crowns and measuring canopy cover are central to estimation of aboveground biomass (Hyyppa et al. 2001, Krofcheck et al. 2016) and tree stem growth, and identification of gaps in forest stands (Vepakomma et al. 2008).

Traditionally, remote sensing based forest inventory requires a large amount of data, a considerable storage capacity that ensures fast transfer of information, and time-consuming computations (Butler 2009). However, openaccess Earth observation data catalogs and associated software packages now provide a useful interface to map land and forest dynamics (Koskinen et al. 2019). In particular, cloud-based computing resources, such as Google Earth Engine (GEE), provide tools for monitoring land cover changes inexpensively (Weiss et al. 2015, Gorelick et al. 2017a). There are various types of imagery available in GEE, including Landsat 8, Sentinel 1 and 2, and MODIS (Moderate Resolution Imaging Spectroradiometer). However, most of the publicly available satellite data cannot be used for the detection of individual tree crowns, as they do not have sufficient spatial resolution. Nevertheless, the GEE and other public platforms provide data with sufficient spatial resolution to delineate crowns of individual trees, such as the images acquired by the United States Department of Agriculture National Agriculture Imagery Program (NAIP). NAIP provides 1-meter resolution true-color images (i.e., blue, green, and red wavelength bands) acquired during the growing season across the continental United States. NAIP began in 2003 with a five-year acquisition cycle but since 2009 , the cycle shortened to threeyears. In 2009, a near-infrared band (NIR) was included, creating the possibility of measuring commonly used ratio-based vegetation indices (Earth Observing System 2020).

GEE provides a suite of tools for pixelbased classification, including supervised classification algorithms such as random forest (RF) (Breiman 2001), naïve Bayesian, and support vector machine (Boser et al. 1992, Cortes \& Vapnik 1995), which are effective tools for mapping heterogeneous landscapes (Congalton 1991, Hansen et al. 2013, Di Palma et al. 2016). Random forest, in particular, has proven to be successful for identification of various types of land cover classes (Joelsson et al. 2006) and enjoys widespread ease of use (Lantz 2019). Monitoring forest vegetation was the subject of many studies that used the GEE for analysis, some focused on divers of change (Huang et al. 2020), some on forest fire (Bar et al. 2020, Barboza Castillo et al. 2020), some on productivity (Yin et al. 2020). However, all supervised classification algorithms remain sensitive to training data selection and sampling (Foody et al. 1995), particularly for long time series analysis when reflectance can vary significantly between observations (Ismail Fawaz et al. 2019).

The current forest inventories using imagery are focused not only on classification of the land cover but also on identification of individual trees, represented by their crown (Bergseng et al. 2015, Yin \& Wang 2016). High-resolution images using only three bands or multiple bands were proven to be instrumental in tree 
crown delineation (Sapkota \& Liang 2018, Weinstein et al. 2020). When elevation data are added to spectral data, the individual tree crown segmentation was significantly improved (Wang et al. 2019). The ability to delineate individual trees is further enhanced if the species tend to grow isolated, like the western juniper (Schriver 2018).

The crown coverage provided by individual trees is of particular importance in areas that exhibited a significant change in land cover, such as from agriculture to urban, or forest to pasture, or for documenting deleterious effects of invasive or noxious species. In central and eastern Oregon, USA, native western juniper (Juniperus occidentalis) has increased its area almost 10 times since 1850. Western juniper has a major impact on the landscape's water availability, particularly in catchments that have peak accumulations of snow water and earlier snowmelt (Kormos et al. 2017). Consequently, juniper alters not only the vegetation but also the fauna (Miller \& Rose 1995, Miller et al. 2005). Major restoration efforts have sought to ensure that the water table remains viable for natural vegetation and streams and that the habitat for wildlife species remains within an acceptable range of variability. To support the success of any restoration initiative, changes in the amount and location of juniper must be known. Therefore, the present study has three objectives: 1) Automatically detect individual western juniper crowns, 2) Estimate forest cover change over a period of eight years, and 3) Assess the impact of estimation methodology on the findings, particularly the effect of training data on the estimation of juniper area.

The objectives of the study align with the restoration efforts carried out by various agencies on the land encroached by western juniper. Considering the large area occupied by juniper, the automatic identification of the resource is mandatory for gauging human and equipment efforts. Furthermore, the urgency of the restoration is guided by the concentration of the juniper across the landscape. Finally, the accuracy of the estimated values depends on the method used in computation (Seppelt \& Richter 2005, Paun et al. 2020); therefore, we will implement two approaches and select the one with lesser errors.

\section{Materials and Methods}

\section{Study area and image acquisition}

The study area of this project covers a surface of $4 \mathrm{~km}^{2}$ (i.e., a square with the side of $2 \mathrm{~km}$ ), which is close to Fossil, Oregon, USA (Figure 1). The land is owned by the US Department of the Interior and is managed by the Bureau of Land Management. The area under consideration is managed mainly for recreation, with minimum disturbance, except the access roads. The study region has a Mediterranean climate with an average annual precipitation of $387 \mathrm{~mm}$ and $152 \mathrm{~mm}$ of average annual

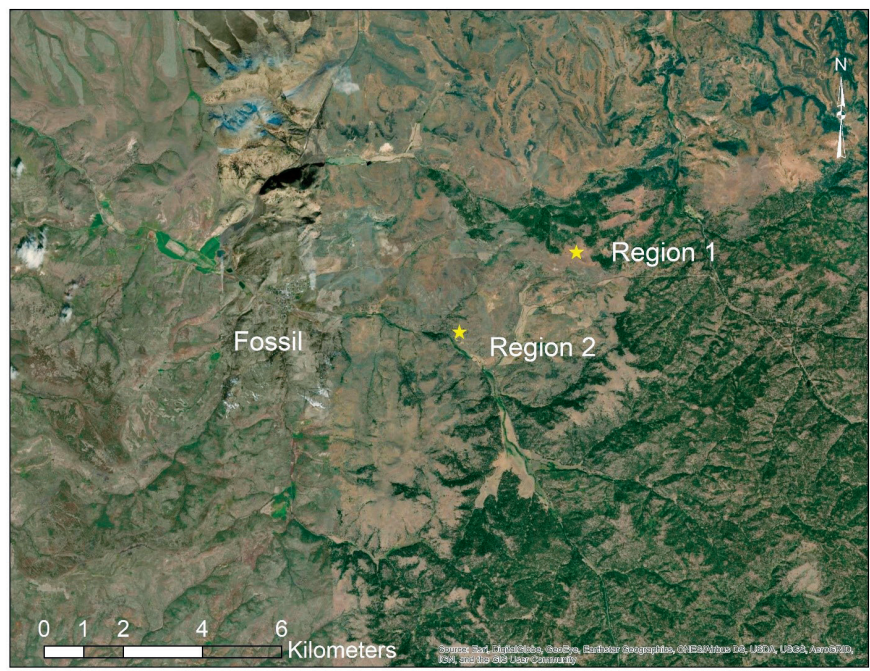

Figure 1 Map of the study area in Fossil, Oregon. 
snowfall. The average temperature of the study area ranges from $5.0^{\circ} \mathrm{C}$ to $17.8^{\circ} \mathrm{C}$ annually (U.S. Climate Data, 2021). To identify western juniper, we selected two subregions for training and testing (Region 1: centered at $120.11948^{\circ}$ longitude and $45.00541^{\circ}$ latitude) and for validation (Region 2: centered at $120.15902^{\circ}$ longitude and $44.98940^{\circ}$ latitude) of the classification algorithm. Within the training area, we selected 300 trees (i.e., 60 different trees for each year), whereas, for testing, we selected 47 trees (i.e., the same for all the years) identified on all NAIP images (Figure 2). The trees were selected such that only juniper were included, and the crown delineation was obvious, which confined the training data only to isolated trees. The selection of trees without intersecting crowns ensured that the training is executed on data without error; therefore, reducing the commission errors.

To identify the junipers, we used NAIP images acquired during the summer and early fall (i.e., from June to September) of 2009, 2011, 2012, 2014, and 2016. The sensor type varied among the years, but on average, the recorded wavelength ranges for the four bands are 420-492 nm (blue), 533-587 nm (green), 604-664 nm (red) and 833-920 nm (near- infrared).

Digital image analysis has the ability to include different indices that support the detection of features of interest (Gandhi et al. 2015). Many studies supported the usage of several indices to characterize vegetation, such as the Normalized Difference Vegetation Index (NDVI), Normalized Difference Water Index (NDWI), Ratio Vegetation Index (RVI), Difference Vegetation Index, Perpendicular Vegetation Index, and Soil-Adjusted Vegetation Index (Xue \&Su 2017). Among them, NDVI is the most widely used (Bhandari et al. 2012) and captures information on both photosynthesis and cell structure using red and near-infrared reflectance: chlorophyll from leaves absorbs visible light during photosynthesis while the cell structure of the leaves reflects nearinfrared light. NDWI has also been proven to be useful for vegetation monitoring since it is sensitive to changes in liquid water content of vegetation canopies (McFeeters 2013a) as well as green vegetation, dry vegetation, and soils (Gao 1996). RVI, which is also sensitive to the chlorophyll content of leaves (Jordan 1969, Quan et al. 2011), has been used for monitoring and estimating green biomass.

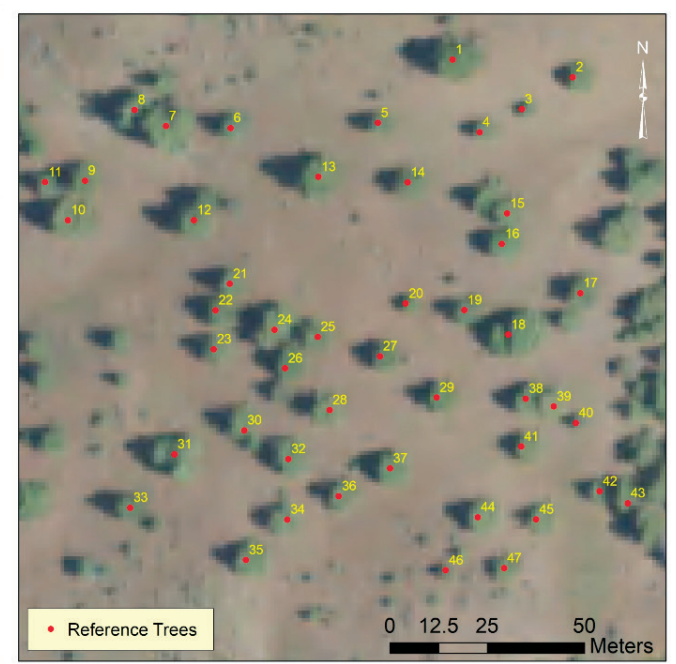

Figure 2 The two regions used in the study: a. training area (colors show different flight years), b. validation area. 
Following the studies of Bhandari et al. (2012), (McFeeters 2013b), and (Jordan 1969, Quan et al. 2011), we calculated three indices proven to detect trees during the growing season: NDVI (Eq. 1), NDWI (Eq. 2), and RVI (Eq. 3):

$$
\begin{aligned}
& N D V I=\frac{N I R-\text { Red }}{N I R+\text { Red }} \quad \text { (Eq. 1) } \\
& N D W I=\frac{\text { Green }-N I R}{\text { Green+NIR }} \quad \text { (Eq. 2) } \\
& R V I=\frac{N I R}{\text { Red }} \quad \text { (Eq. 3) }
\end{aligned}
$$

where: NIR is the reflectance in the near-infrared band, commonly from $700 \mathrm{~nm}$ to $1100 \mathrm{~nm}$;

Red is the reflectance in the red band (from 635 to $700 \mathrm{~nm}$ );

Green is the reflectance in the green wave band, centered at $540 \mathrm{~nm}$.

\section{Image classification}

To identify western juniper crowns from NAIP images, we performed a supervised classification with the RF algorithm (Breiman 2001), as implemented in the GEE. The RF classifier was implemented following the recommendations of Chicco (2017) by using $70 \%$ of the data for training and $30 \%$ for testing from data collected in Region 1. To assess the impact of the training approach on the results, we created two training datasets, one using yearly images separately (subsequently referred to as Method 1) and one merging all images, irrespective of image years (subsequently referred to as Method 2) (Figure 3). An average of 206 training areas were selected for each year. We chose five classes representative of the study area: grass, barren (i.e., exposed soil and rocks), roads, shadow, and trees (i.e., western juniper). The five classes were selected to reduce the variability within classes while increasing the differences

between classes. We followed the recommendations of Comber et al. (2012), which considered the shadow of trees as noise, and created a new class called "shadow", separate from the tree crown.

\section{Study methods}

In total, 303 crowns were visually identified, 212 of which were used to train the RF algorithm classifier. The parameters defining the RF were chosen through trial and error, with the emphasis being placed on the number of decision trees and the seeds. We found that 100 decision trees and 19 seeds while keeping all other parameters at the default values suggested by the GEE (e.g., mean leaf population, bag fraction, max nodes, variables per split), supplied the most accurate results for the testing and validation trees. The classified images were further enhanced using the convolutions. The GEE provides a set of convolution algorithms (Gorelick et al. 2017b), with kernels of different shapes and weights, which we used for increasing the separation
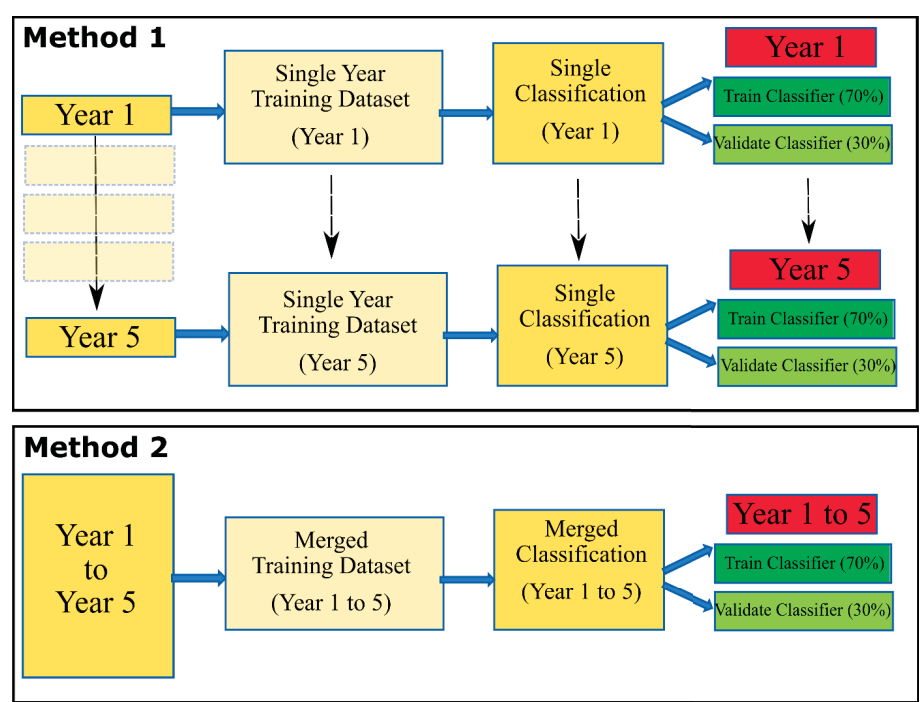

Figure 3 The structure of the two methods used to create the training data. 
between the different classes. We tried various kernels, including square, circle, and gaussian, and different weights, and we found that the images processed with a Gaussian kernel having the radius 0.9 , the sigma 1 , and the values were normalized to add up 1 led to results with the smallest number of errors. We further enhanced the convoluted images with two morphological operations, namely dilation and erosion. Morphological dilation improves the visibility of the objects, while morphological erosion assists in removing the islands and small objects within the image. Finally, the delineation of individual tree was executed by converting the tree class from the raster to vector, which contains only the individual tree canopies (Figure 4).

\section{Accuracy Assessment}

To assess the accuracy of tree detection, we used three metrics similar to Zhan et al. (2005) and Zhang et al. (2019): completeness (Eq. 4), correctness (Eq. 5), mean accuracy detection (Eq. 6). In addition to the three metrics, we calculated the number of omitted trees (i.e., false negative) and the number of committed trees (i.e., false positive). The location of a tree was computed as the centroid of the predicted crown. We considered that a tree whose location is estimated inside the crown of a visually identified tree was predicted accurately. Using the previously mentioned assumptions, we estimated location bias (Eq.7) and precision (Eq. 8), similar to (Hogg et al. 2012).

$$
\begin{aligned}
& \text { Compleatness }=\frac{\mathrm{N}_{\text {match }}}{\mathrm{N}_{\text {reference }}} \text { (Eq.4) } \\
& \text { Correctness }=\frac{\mathrm{N}_{\text {match }}}{\mathrm{N}_{\text {segmented }}} \text { (Eq. 5) } \\
& \text { Mean accuracy detection }=\mathrm{MAD}=\frac{2 \mathrm{~N}_{\text {match }}}{\left(\mathrm{N}_{\text {ref }}+\mathrm{N}_{\text {segmented })}\right.} \text { (Eq. 6) } \\
& \text { Bias }=\frac{\sum_{i=1}^{n}\left(\text { location }_{\text {segmented }} \text {-location } \text { reference }_{\text {ef }}\right)}{N_{\text {match }}} \text { (Eq. 7) } \\
& \text { Precision }=\sqrt{\frac{\sum_{i=1}^{n}\left(\text { location }_{\text {segmented }}-\text { location }_{\text {reference }}\right)^{2}}{N_{\text {match }}}} \text { (Eq. 8) }
\end{aligned}
$$

where: $\mathrm{N}_{\text {match }}$ refers to the number of found reference trees;

$\mathrm{N}_{\text {reference }}$ is the total number of reference trees; $\mathrm{N}_{\text {segmented }}$ is the total number of trees segmented; Location $_{\text {segmented }}$ is the predicted easting or northing;

Location $_{\text {reference }}$ is the visually interpreted easting or northing.



Figure 4 The flowchart of the important steps applied in this study. 


\section{Results and Discussion}

Individual tree crown detection

RF performed better when the individual years were used for training compared to the merged years (Table 1). Even though we selected the same time period and sampling region, the spectral signature of various classes tended to vary between years, possibly due to different sun angles, sensor performance, and image noise (Lillesand et al. 2015). The tree crown identification method that provided the results with the largest completeness, correctness, and MAD was based on a Gaussian kernel (Table 1), which was subsequently used throughout the study.

The testing of the RF algorithm on the 47 validation trees (Figure 5) revealed that the number of segmented trees $\left(\mathrm{N}_{\text {match }}\right)$ matched unevenly with reference trees $\left(\mathrm{N}_{\text {reference }}\right)$, with the 2011 being prone to omission and commission errors (Table 2), irrespective of the method. Regardless of the year, Method 1 outperformed Method 2 by at least $13 \%$ (i.e., $\mathrm{N}_{\text {match }}=35$ vs. $\mathrm{N}_{\text {match }}=27$ ). For the 2011 and 2012 years, Method 2 exhibited a larger commission error than Method 1, with 20 extra trees rather than 12 trees, respectively. The commission error was higher, possibly due to the effects of shadow (Figure 6).



Figure 5 Classified image and the testing trees.

Table 1 Summary of training and testing tree accuracies. Individual years refer to Method 1, and Merged years refer to Method 2.

\begin{tabular}{lcccccc}
\hline \multirow{2}{*}{ Measure } & \multicolumn{5}{c}{ Individual years } & Merged years \\
\cline { 2 - 7 } & $\mathbf{2 0 0 9}$ & $\mathbf{2 0 1 1}$ & $\mathbf{2 0 1 2}$ & $\mathbf{2 0 1 4}$ & $\mathbf{2 0 1 6}$ & $\mathbf{2 0 0 9 - 2 0 1 6}$ \\
\hline Completeness & & & & & & \\
Training & 1.00 & 1.00 & 1.00 & 1.00 & 1.00 & 0.98 \\
Testing & 0.87 & 0.66 & 0.88 & 0.82 & 0.89 & 0.71 \\
Correctness & & & & & & \\
\hline Training & 1.00 & 1.00 & 0.98 & 1.00 & 1.00 & 0.99 \\
Testing & 1.00 & 0.72 & 0.75 & 0.95 & 0.91 & 0.76 \\
MAD & & & & & & \\
Training & 1.00 & 1.00 & 0.99 & 1.00 & 1.00 & 0.98 \\
Testing & 0.93 & 0.70 & 0.81 & 0.88 & 0.89 & 0.75 \\
\hline
\end{tabular}




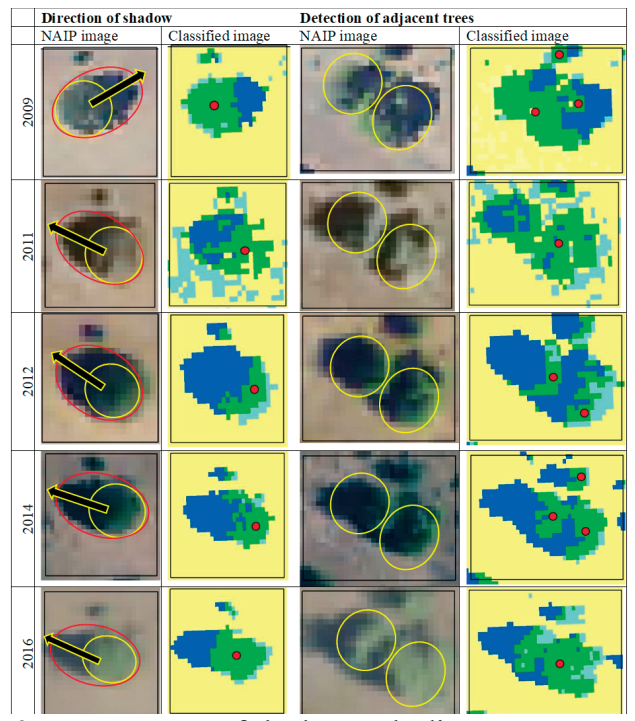

Figure 6 Impact of shadow and adjacent trees on individual tree crown delineation.

Depending on the direction of the sun, tree branches could appear as separate trees

(Comber et al. 2012). The estimated correctness for each year was substantially higher for Method 1, particularly for 2009, 2014, and 2016, which showed the correctness values of $94 \%$ and $100 \%$ (Table 2). However, observed values from 2011 and 2012 reported slightly lower correctness values, at most $90 \%$. Consequently, the algorithm performance depends on the texture, shadow, tone or color, size, and shape (Gibson 2014, Svatoňová \& Šikl 2017, Vahidi et al. 2018).

The lowest estimated completeness was observed in Method 2 (19\% for 2011 imagery), while the highest estimated completeness was reported by Method 1 (94\% for 2009 imagery). The calculated average completeness for Method 1 is $74 \%$, which is 1.3 times higher than the average completeness measured with Method 2 (57\%). The estimated average MAD is greater for Method 1 (i.e., 82\%) compared with Method 2 (i.e., 67\%) with the 2009 image showing the highest value (i.e., 94\%). Overall, the accuracy assessment measures suggest that NAIP imagery acquired in 2011 and 2012 did not perform well, probably because of the low contrast of each set of images (Vahidi et al. 2018), due to various effects such as haze and smoke (Poznanovic et al. 2014). The estimated average location bias, expressed in easting and northing coordinates, for Method 1 were $0.16 \mathrm{~m}$ and $-0.22 \mathrm{~m}$, respectively, whereas for Method 2 , the predicted northing had a southern bias of $-0.11 \mathrm{~m}$, and the easting was westward 0.05 $\mathrm{m}$ (Table 3). The estimated average positional accuracy was higher for the Method 1 (i.e., $\mathrm{RMSE}_{\text {easting }}=0.90 \mathrm{~m}$ and $\mathrm{RMSE}_{\text {northing }}=1.14$ $\mathrm{m}$ ) compared to Method 2 (i.e., $\mathrm{RMSE}_{\text {easting }}=$ $1.08 \mathrm{~m}$ and $\mathrm{RMSE}_{\text {northing }}=1.26 \mathrm{~m}$ ) (Table 3). The average Euclidean distance between the estimated crown centroid and the location of the validation trees was lower for Method 1 (1.45 m) than for Method $2(1.68 \mathrm{~m})$. The estimated precision for each year was higher for Method 1 , specifically in 2009,2014 , and 2016, which is less than the resolution of the images, indicating the potential use of the RF algorithm to detect trees based on the NAIP imagery.

Table 2 Summary statistics of tree detection on the validation area imagery from 2009 to 2016.

\begin{tabular}{lcccccc|cccccc}
\hline \multirow{2}{*}{ Measure } & \multicolumn{1}{l|}{ Method 1 } & \multicolumn{10}{c|}{ Method 2 } \\
\cline { 2 - 13 } & $\mathbf{2 0 0 9}$ & $\mathbf{2 0 1 1}$ & $\mathbf{2 0 1 2}$ & $\mathbf{2 0 1 4}$ & $\mathbf{2 0 1 6}$ & Avg. & $\mathbf{2 0 0 9}$ & $\mathbf{2 0 1 1}$ & $\mathbf{2 0 1 2}$ & $\mathbf{2 0 1 4}$ & $\mathbf{2 0 1 6}$ & Avg. \\
\hline $\mathrm{N}_{\text {reference }}$ & 47 & 47 & 47 & 47 & 47 & 47 & 47 & 47 & 47 & 47 & 47 & 47 \\
$\mathrm{~N}_{\text {commission }}$ & 3 & 3 & 4 & 0 & 0 & 2 & 4 & 3 & 3 & 5 & 3 & 4 \\
$\mathrm{~N}_{\text {omission }}$ & 3 & 20 & 25 & 6 & 7 & 12 & 19 & 38 & 11 & 16 & 17 & 20 \\
$\mathrm{~N}_{\text {match }}$ & 44 & 27 & 22 & 41 & 40 & 35 & 28 & 9 & 36 & 31 & 30 & 27 \\
$\mathrm{~N}_{\text {segmented }}$ & 47 & 30 & 26 & 41 & 40 & 37 & 32 & 12 & 39 & 36 & 33 & 30 \\
Compl. (\%) & 94 & 57 & 47 & 87 & 85 & 74 & 60 & 19 & 77 & 66 & 64 & 57 \\
Correct (\%) & 94 & 90 & 85 & 100 & 100 & 94 & 88 & 75 & 92 & 86 & 91 & 86 \\
MAD (\%) & 94 & 70 & 60 & 93 & 92 & 82 & 71 & 31 & 84 & 75 & 75 & 67 \\
\hline
\end{tabular}


Table 3 Summary of bias and precision values. Avg. refers to the average and Euc.distance refers to the Euclidian distance between the centroid of segmented crown and the location of the validation trees.

\begin{tabular}{lcccccc|cccccc}
\hline \multirow{2}{*}{ Measure } & \multicolumn{1}{l}{ Method 1 } & \multicolumn{1}{c|}{} & \multicolumn{1}{l}{ Method 2 } \\
\cline { 2 - 12 } & $\mathbf{2 0 0 9}$ & $\mathbf{2 0 1 1}$ & $\mathbf{2 0 1 2}$ & $\mathbf{2 0 1 4}$ & $\mathbf{2 0 1 6}$ & Avg. & $\mathbf{2 0 0 9}$ & $\mathbf{2 0 1 1}$ & $\mathbf{2 0 1 2}$ & $\mathbf{2 0 1 4}$ & $\mathbf{2 0 1 6}$ & Avg. \\
\hline Bias (m) & & & & & & & & & & & & \\
East & -0.08 & 0.49 & -0.12 & 0.38 & 0.11 & 0.16 & -0.52 & -1.02 & 0.11 & 0.66 & 0.23 & -0.11 \\
North & -0.36 & -0.22 & -0.46 & -0.28 & 0.23 & -0.22 & -0.46 & -0.25 & 0.31 & 0.31 & 0.33 & 0.05 \\
Precis (m) & & & & & & & & & & & & \\
East & 0.71 & 1.08 & 1.06 & 0.79 & 0.88 & 0.90 & 0.99 & 1.41 & 0.68 & 1.14 & 1.16 & 1.08 \\
North & 0.90 & 1.49 & 1.33 & 0.98 & 0.98 & 1.14 & 1.07 & 1.07 & 1.53 & 1.30 & 1.33 & 1.26 \\
Euc. Dist. (m) & 1.14 & 1.85 & 1.71 & 1.25 & 1.32 & 1.45 & 1.46 & 1.77 & 1.68 & 1.72 & 1.77 & 1.68 \\
\hline
\end{tabular}

However, visual interpretation of remotely sensed images involves a significant amount of subjective decisions associated with human factors, such as experience, expertise, and onsite knowledge (Hall 2003, Svatonova 2016, Hoffman \& Markman 2019). Hence, prior knowledge and onsite information (actual reference data, coordinates) could increase the accuracy of tree detection and location.

\section{Forest cover change}

The western juniper has a significant impact on hydrological cycles and on the wildlife habitat. Therefore, accurate estimation of the area covered with western juniper is important for the restoration efforts. Due to the lower overall testing accuracy of Method 2, we assessed the temporal changes in crown cover using only Method 1 . The crown area exhibits a sinusoidal pattern through time (Figure 7), with an increase from 2009 to 2011, followed by a decrease from 2011 to 2012 , then an increase from 2012 to 2014 .

The decrease in canopy cover for 2012, 2014, and 2016 compared with 2011 is due to the significant increase in shadow (Figure 5). The difference between shadow and canopy is probably due to the low elevation of the sun when the images were acquired, which unevenly affected the reflectance across the canopy. The sides facing the sun reflected more radiance, whereas the obstructed part of the crown reflected less, making it more similar to the shaded ground. The distinction between the shadow and canopy affects the accuracy of the estimated forest cover, likely underestimating the actual coverage, as seen in Figure 6. Nevertheless, even with a smaller than real surface, the analysis shows an increase in the area of western juniper, pointing toward the urgency of restoration efforts.

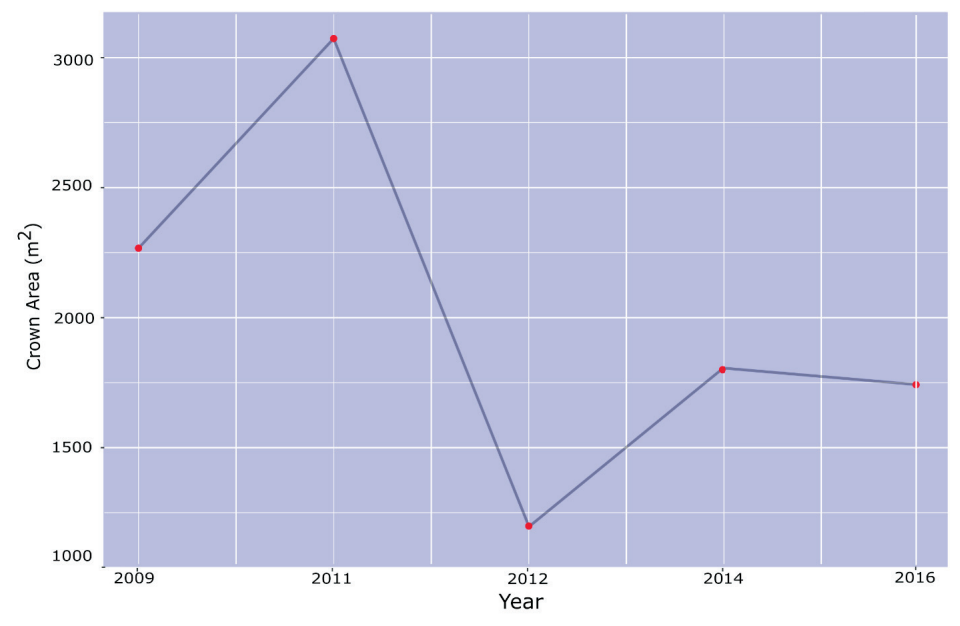

Figure 7 Estimated forest cover change from 2009 to 2016 using method 1. 


\section{Conclusion}

The present study proposed an automated approach to detect the location of individual trees and canopy area of western juniper using 1-m resolution NAIP imagery available in GEE. The tree and crown detection algorithm was trained with two methods: one using individual years and one using all years combined. The estimated overall training and testing accuracies were higher when the training was carried out on individual years rather than on all years combined. Therefore, the classification should be implemented using annual information to avoid inclusion of spectral variation due to the sensor type, weather, atmospheric condition, and position of the sun with respect to the area. Our results based on training the RF algorithm with yearly data showed encouraging performance with respect to completeness, correctness, and MAD. As in most remote sensing analyses, the classification of tree canopies not only was tedious but also iterative, as many runs were executed to properly identify the importance of the attributes describing the landscape, including canopy shadow, texture, and tone. Even when a separate class was introduced for shadow, the tree detection did not perform well, especially in 2011 and 2012, potentially due to tone and texture. The reduced accuracy in tree detection was reflected by the lower correctness, completeness, and MAD in 2011 and 2012. The estimated tree location for Method 2 indicated southern bias in latitude direction and westward bias in longitude direction, whereas an inverse relationship was observed for Method 1. Many parameters play a significant role in tree identification and location using RF algorithm (e.g., the ratio of training/validation data, the number of decision trees, kernel method, and radius). Future studies should try to preprocess the images to remove or reduce the impact of shadow. Finally, because of its simplicity, the algorithm presented in this study can be extended to large areas with limited effort.

\section{References}

Bar S., Parida B.R., Pandey A.C., 2020. Landsat-8 and Sentinel-2 based Forest fire burn area mapping using machine learning algorithms on GEE cloud platform over Uttarakhand, Western Himalaya. Remote Sensing Applications: Society and Environment 18:100324. https://doi.org/10.1016/j.rsase.2020.100324

Barboza Castillo E., Turpo Cayo E.Y., de Almeida C.M., et al., 2020. Monitoring Wildfires in the Northeastern Peruvian Amazon Using Landsat-8 and Sentinel-2 Imagery in the GEE Platform. ISPRS International Journal of Geo-Information 9:564. https://doi. org/10.3390/ijgi9100564

Bergseng E., Ørka H.O., Næsset E., Gobakken T., 2015. Assessing forest inventory information obtained from different inventory approaches and remote sensing data sources. Annals of Forest Science 72:33-45. https://doi. org/10.1007/s13595-014-0389-x

Bhandari A.K., Kumar A., Singh G.K., 2012. Feature Extraction using Normalized Difference Vegetation Index (NDVI): A Case Study of Jabalpur City. Procedia Technology 6:612-621. https://doi.org/10.1016/j. protcy.2012.10.074

Boser B.E., Guyon I.M., Vapnik V.N., 1992. A training algorithm for optimal margin classifiers. In: Proceedings of the fifth annual workshop on Computational learning theory. Association for Computing Machinery, Pittsburgh, Pennsylvania, USA, pp 144-152.

Breiman L., 2001. Random Forests. Machine Learning 45:5-32. https://doi.org/10.1023/a:1010933404324

Butler R.A., 2009. Google's Earth Engine to help tropical countries monitor forests. In: Mongabay Environmental News. https://news.mongabay.com/2009/12/googlesearth-engine-to-help-tropical-countries-monitorforests/. Accessed 15 Apr 2020.

Chicco D., 2017. Ten quick tips for machine learning in computational biology. BioData Mining 10:35. https:// doi.org/10.1186/s13040-017-0155-3

Comber A., Umezaki M., Zhou R., et al., 2012. Using shadows in high-resolution imagery to determine building height. Remote Sensing Letters 3:551-556. https://doi.org/10.1080/01431161.2011.635161

Congalton R.G., 1991. A review of assessing the accuracy of classifications of remotely sensed data. Remote Sensing of Environment 37:35-46. https://doi. org/10.1016/0034-4257(91)90048-B

Cortes C., Vapnik V., 1995. Support-vector networks. Mach Learn 20:273-297. https://doi.org/10.1007/ BF00994018

Earth Observing System, 2020. NAIP (National Agriculture Imagery Program) [WWW Document]. Earth Obs. Syst. URL https://eos.com/naip/ (accessed 4.21.20). 
Foody G.M., McCullooch M.B., Yates W.B., 1995. The effect of training set size and composition on artificial neural network classification. International Journal of Remote Sensing 16:1707-1723. https://doi. org/10.1080/01431169508954507

Gandhi G.M., Parthiban S., Thummalu N., Christy A., 2015. Ndvi: Vegetation change detection using remote sensing and GIS - A case study of Vellore District. Procedia Computer Science 57:1199-1210. https://doi. org/10.1016/j.procs.2015.07.415

Gao B., 1996. NDWI-A normalized difference water index for remote sensing of vegetation liquid water from space. Remote Sensing of Environment 58:257266. https://doi.org/10.1016/S0034-4257(96)00067-3

Gatziolis D., Lienard J.F., Vogs A., Strigul N.S., 2015. 3D tree dimensionality assessment using photogrammetry and small unmanned aerial vehicles. PLoS One 10:. https://doi.org/10.1371/journal.pone.0137765

Gibson J.J., 2014. The ecological approach to visual perception: Classic Edition. Psychology Press

Gorelick N., Hancher M., Dixon M., et al., 2017a. Google Earth Engine: Planetary-scale geospatial analysis for everyone. Remote Sensing of Environment 202:18-27. https://doi.org/10.1016/j.rse.2017.06.031

Gorelick N., Hancher M., Dixon M., et al., 2017b. Google Earth Engine: Planetary-scale geospatial analysis for everyone. Remote Sensing of Environment 202:18-27. https://doi.org/10.1016/j.rse.2017.06.031

Hall R.J., 2003. The Roles of Aerial Photographs in Forestry Remote Sensing Image Analysis. In: Wulder MA, Franklin SE (eds) Remote Sensing of Forest Environments: Concepts and Case Studies. Springer US, Boston, MA, pp 47-75.

Hansen M.C., Potapov P.V., Moore R., et al., 2013. HighResolution Global Maps of 21st-Century Forest Cover Change. Science 342:850-853. https://doi.org/10.1126/ science. 1244693

Hoffman R.R., Markman A.B., 2019. Interpreting Remote Sensing Imagery: Human Factors. CRC Press.

Hogg R.V., McKean J., Craig A.T., 2012. Introduction to Mathematical Statistics, 7 th edn. Pearson.

Huang C., Yang Q., Guo Y., et al., 2020. The pattern, change and driven factors of vegetation cover in the Qin Mountains region. Sci Rep 10:20591. https://doi. org/10.1038/s41598-020-75845-5

Hyyppa J., Kelle O., Lehikoinen M., Inkinen M., 2001. A segmentation-based method to retrieve stem volume estimates from 3-D tree height models produced by laser scanners. IEEE Transactions on Geoscience and Remote Sensing 39:969-975.

Ismail Fawaz H., Forestier G., Weber J., et al., 2019. Deep learning for time series classification: a review. Data Min Knowl Disc 33:917-963. https://doi.org/10.1007/ s10618-019-00619-1

Joelsson S.R., Benediktsson J.A., Sveinsson J.R., et al., 2006. Random forest classification of remote sensing data. in: Signal and image processing for remote sensing. https://www.taylorfrancis.com/. Accessed 18 Apr 2020.
Jordan C.F., 1969. Derivation of Leaf-Area Index from Quality of light on the forest floor. Ecology 50:663666. https://doi.org/10.2307/1936256

Kormos P.R., Marks D., Pierson F.B., et al., 2017. Ecosystem Water availability in juniper versus sagebrush snow-dominated rangelands. Rangeland Ecology \& Management 70:116-128. https://doi. org/10.1016/j.rama.2016.05.003

Koskinen J., Leinonen U., Vollrath A., et al., 2019. Participatory mapping of forest plantations with Open Foris and Google Earth Engine. ISPRS Journal of Photogrammetry and Remote Sensing 148:63-74. https://doi.org/10.1016/j. isprsjprs.2018.12.011

Krofcheck D.J., Litvak M.E., Lippitt C.D., Neuenschwander A., 2016. Woody biomass estimation in a southwestern US juniper savanna using lidarderived clumped tree segmentation and existing allometries. Remote Sensing 8:453.

Lantz B., 2019. Machine Learning with R, 3rd edn. Packt Publishing, Birgmingham UK.

Lillesand T., Kiefer R.W., Chipman J., 2015. Remote Sensing and Image Interpretation. John Wiley \& Sons.

McFeeters S.K., 2013a. Using the Normalized Difference Water Index (NDWI) within a Geographic Information System to Detect Swimming Pools for Mosquito Abatement: A Practical Approach. Remote Sensing 5:3544-3561. https://doi.org/10.3390/rs5073544

McFeeters S.K., 2013b. Using the Normalized Difference Water Index (NDWI) within a Geographic Information System to Detect Swimming Pools for Mosquito Abatement: A Practical Approach. Remote Sensing 5:3544-3561. https://doi.org/10.3390/rs5073544

Meyer F., Beucher S., 1990. Morphological segmentation. Journal of Visual Communication and Image Representation 1:21-46. https://doi.org/10.1016/10473203(90)90014-M

Miller R.F., Bates J.D., Svejcar T.J., et al., 2005. Biology, Ecology, and Management of Western Juniper (Juniperus occidentalis). Oregon State University, Corvallis OR.

Miller R.F., Rose J.A., 1995. Historic expansion of Juniperus occidentalis (western juniper) in southeastern Oregon. The Great Basin Naturalist 55:37-45.

Paun M., Gunaime N., Strimbu B.M., 2020. Impact of Algorithm Selection on Modeling Ozone Pollution: A Perspective on Box and Tiao (1975). Forests 11:1311. https://doi.org/10.3390/f11121311

Popescu S.C., Wynne R.H., Nelson R.F., 2003. Measuring individual tree crown diameter with lidar and assessing its influence on estimating forest volume and biomass. Canadian Journal of Remote Sensing 29:564-577. https://doi.org/10.5589/m03-027

Poznanovic A.J., Falkowski M.J., Maclean A.L., et al., 2014. An Accuracy Assessment of Tree Detection Algorithms in Juniper Woodlands. https://orst.library.ingentaconnect. com/content/asprs/pers/2014/00000080/00000007/ art00002. Accessed 17 Jun 2021. 
Quan Z., Xianfeng Z., Miao J., 2011. Eco-environment variable estimation from remote sensed data and ecoenvironment assessment: models and system. Acta Botanica Sinica 47:1073-1080

Sapkota B.B., Liang L., 2018. A multistep approach to classify full canopy and leafless trees in bottomland hardwoods using very high-resolution imagery. Journal of Sustainable Forestry 37:339-356. https://doi.org/10. 1080/10549811.2017.1409637

Schriver R., 2018. Landscape Inventory and Harvest Strategies for Individual Western Juniper in Eastern Oregon. MS, Oregon State University.

Seppelt R., Richter O., 2005. "It was an artefact not the result": A note on systems dynamic model development tools. Environmental Modelling \& Software 20:15431548. https://doi.org/10.1016/j.envsoft.2004.12.004

Svatonova H., 2016. Analysis of Visual Interpretation of Satellite Data. Int Arch Photogramm Remote Sens Spatial Inf Sci XLI-B2:675-681. https://doi. org/10.5194/isprsarchives-XLI-B2-675-2016

Svatoňová H., Šikl R., 2017. Cognitive Aspects of Interpretation of Image Data. In: Hošková-Mayerová Š, Maturo F, Kacprzyk J (eds) Mathematical-Statistical Models and Qualitative Theories for Economic and Social Sciences. Springer International Publishing, Cham, pp 161-175.

U.S. Climate Data, 2021. Weather averages Fossil, OR

Vahidi H., Klinkenberg B., Johnson B.A., et al., 2018. Mapping the Individual Trees in Urban Orchards by Incorporating Volunteered Geographic Information and Very High Resolution Optical Remotely Sensed Data: A Template Matching-Based Approach. Remote Sensing 10:1134. https://doi.org/10.3390/rs10071134

Vepakomma U., St-Onge B., Kneeshaw D., 2008. Spatially explicit characterization of boreal forest gap dynamics using multi-temporal lidar data. Remote Sensing of Environment 112:2326-2340. https://doi.org/10.1016/j. rse.2007.10.001

Wang K., Wang T., Liu X., 2019. A Review: Individual Tree Species Classification Using Integrated Airborne LiDAR and Optical Imagery with a Focus on the Urban Environment. Forests 10:1. https://doi.org/10.3390/ f10010001
Wang L., Gong P., Biging G.S., 2004. Individual Tree-Crown Delineation and Treetop Detection in High-Spatial-Resolution Aerial Imagery. https://www.ingentaconnect.com/content/asprs/ pers/2004/00000070/00000003/art00007. Accessed 18 Apr 2020.

Weinstein B.G., Marconi S., Aubry-Kientz M., et al., 2020. DeepForest: A Python package for RGB deep learning tree crown delineation. Methods in Ecology and Evolution 11:1743-1751. https://doi.org/10.1111/2041210X.13472

Weiss S.M., Indurkhya N., Zhang T., 2015. Case Studies. In: Weiss SM, Indurkhya N, Zhang T (eds) Fundamentals of Predictive Text Mining. Springer, London, pp 165-201.

Xue J., Su B., 2017. Significant Remote Sensing Vegetation Indices: A Review of Developments and Applications. In: Journal of Sensors. https://www.hindawi.com/ journals/js/2017/1353691/. Accessed 1 Apr 2020.

Yin D., Wang L., 2016. How to assess the accuracy of the individual tree-based forest inventory derived from remotely sensed data: a review. International Journal of Remote Sensing 37:4521-4553. https://doi.org/10.1080 /01431161.2016.1214302

Yin S., Wu W., Zhao X., et al., 2020. Understanding spatiotemporal patterns of global forest NPP using a data-driven method based on GEE. PLOS ONE 15:e0230098. https://doi.org/10.1371/journal. pone. 0230098

Zhan Q., Molenaar M., Tempfli K., Shi W., 2005. Quality assessment for geo-spatial objects derived from remotely sensed data. International Journal of Remote Sensing 26:2953-2974. https://doi. org/10.1080/01431160500057764

Zhang W., Wan P., Wang T., et al., 2019. A Novel Approach for the Detection of Standing Tree Stems from PlotLevel Terrestrial Laser Scanning Data. Remote Sensing 11:211. https://doi.org/10.3390/rs11020211 